\title{
Zwei neue deutsche Käfer von Borkum,
}

\author{
beschrieben von
}

Prof. Dr. Oskar Schneider (Blasewitz).

Heterocerus burchanensis O. Schndr.: H. britannico Kuw. similis, sed major, thorace non minus dense crinito elytris, minus rotundato, elytris plus quam dimidiata parte sed nunquam duplo longioribus quam latis. - Long. 2.40-3.40 mill.

Auf diesen kleinsten aller bisher in Norddeutschland nachgewiesenen Heterocerus palst vieles, das Kuwert dem leider nur nach einem einzigen, jetzt wohl in der Sammlung Oberthür's befindlichen Thiere beschriebenen, also schwer in Vergleich zu ziehenden $\boldsymbol{H}$. britannicus zuschreibt: Das Halsschild ist mehr oder minder, doch immer deutlich breiter als die Fld. und hat eine hervorstechend rothe Mittellinie, sowie verwaschen rothe Seiten; die Beine und das Hinterleibsende (oft auch die Aufsenränder der Abdominalsegmente) sind röthlich; das Kopfschild der $\sigma^{\star}$ scheint vorn immer schwach gehöckert zu sein, die Tibien sind nach ihrem Ende hin stark verbreitert, - aber H. burch. ist stets gröfser (als 2 mill.), das Halssch. ist von den sehr stumpfen Hinterecken nach vorn mit nur mälsig oder kaum gebogenen Rändern bis über die Mitte etwas erweitert und dann im Bogen schnell verjüngt und zeigt, wenn man es nicht von derselben Seite wie die Fld., sondern der anderen Stellung der Haare entsprechend in entgegengesetzter Richtung betrachtet, durchaus nicht eine "weniger dichte", sondern eher eine dichtere und jedenfalls längere Behaarung als die Decken, und diese sind nie doppelt, sondern nur etwa $1 \frac{3}{4} \mathrm{mal}$ so lang als breit. Die rothe Zeichnung der ziemlich dicht feinpunktirten Fld. ist durchaus nicht immer "undeutlich", sondern meist wohl erkennbar und besteht, entsprechend der maritimus-Gruppe Kuwert's, in einer von dem Schulterrande schief nach der Naht verlaufenden und sich verjüngenden, etwas gebogenen Binde, einem hinter der Mitte liegenden, schief gestellten, nach der Spitze der Decken geöffneten Halbkreise und einem länglich-runden Flecke neben dem hinteren Theile der Naht, aufserdem aber ist auch das Spitzenende und der hintere Rand der Fld. roth gesäumt; selten zeigt sich die Vorderbinde mit der mittlen an der $\mathrm{Naht}$ schwach verbunden. Das Halssch. ist meist etwas heller als die oft tief schwarzen Fld., 
mehr oder weniger röthlichbraun; selten ist bei unten schwarzen, also ausgefärbten Stücken die ganze Oberfläche rothbraun mit bräunlichroth sich abhebender Zeichnung. Der vordere Theil des Prosternums ist (wie bei maritimus Gen.) röthlich, der breite Rand beiderseits röthlich oder gelblich. Die rothe Färbung der Spitze und der Seitenränder des Abdomens ist bald, besonders bei im Ganzen sehr dunklen Individuen, fast verschwindend, bald sehr deutlich und breit. Bei ganz reinen Stücken erscheint die Behaarung der Fld. aus dichtstehenden, kurzen, halb aufgerichteten, gelblichen und aus sparsamer stehenden, so wenig längeren Haaren gebildet, dafs die beiden Haarsorten nur bei starker Vergröfserung unterscheidbar sind; auf dem Thorax haben die Haare beider Arten etwas gröfsere Länge und aufserdem stehen auf demselben oft vereinzelte, viel längere Haarborsten, deren sich auf dem dicht und weifslich behaarten Kopfe und am Ende des Abdomens in gröfserer Menge zeigen. H. burchanensis dürfte zwischen H. britannicus Kuw. und $H$. maritimus Gen. einzureihen sein; von letzterem unterscheidet er sich durch breiteres, hinten stumpfwinkeliges Halssch, verhältnifsmäfsig längere Fld., stärkere Röthung des Abdomens u. a. Ganze Schenkellinien und die Form der Fühler verweisen $H$. burchanensis in Seidlitz' (Fauna baltica 2. Aufl.) 4. Gruppe der Heterocerus.

Fundort: Insel Borkum (Burchana der alten Römer), wo das Thierchen lediglich in der schlickigen Erde der senkrechten Wände haust, die zu dem Brackwasser führenden Hoop und den Mündungen der in dasselbe auslaufenden Gräben abfallen.

Otiorhynchus frisius O. Schndr.: O. ligneo Ol. similis, sed major, multo angustior, altius magisque fornicatus, thorace in margine aequabilius rotundato, longius a basi latissimo, thorace et elytris minus granulatis, humeris magis rotundatis, rostro rubro. - Long. $4.5-6$ mill.

Durch Kopf und Fühler, die Körnelung des kiellosen Halssch., die Skulptur und die Borstenreihen der Fld. und die Beine an 0 . ligneus erinnernd, aber gröfser (sehr selten unter 5, meist $5.5-6$ mill.), höher und oben stärker gewölbt und auffallend schmäler (nie "höchstens $2 \frac{1}{3} \mathrm{mal}$ so lang als breit", wie Stierlin für seine 12 . Rotte der $O t$. angiebt, sondern mindestens $2 \frac{1}{2}$ mal). Auf der Stirn fehlt das tiefe regelmälsige Längsgrübchen, das meine ligneus aufweisen, oder es ist nur durch eine flache, unregelmälsige Vertiefung angedeutet. Das Halssch. ist etwas gleichmälsiger gerundet, seine grölste Breite nicht wesentlich oder doch nicht so weit hinter der Mitte wie bei meinen 6 ligneus aus 
Südfrankreich und von Lugano, die Körnelung flacher. Die Fld. sind nicht "mehr als doppelt so breit als das Halssch." und nicht "höchstens $1 \frac{1}{3}$-", sondern $1 \frac{1}{2}$ - und mehr mal so lang als breit; die Schulterecken flacher gerundet, die Zwischenräume zwischen den stark punktirten Streifen meist breiter als diese (besonders bei den breiteren + 우), weniger stark als bei ligneus oder kaum gekörnt. Die ausgefärbten Stücke sind auf der Oberseite schwarz, der Rüssel (bei ligneus schwarz, höchstens an der Spitze röthlich) ist stets ganz, die Unterseite, besonders die Vorderbrust und das Abdomen, meist rothbraun, Fühler und Beine bräunlichroth, weit heller als bei ligneus. Trotz Aehnlichkeit mit ligneus doch ihm nicht gleich und kaum neben demselben in Stierlin's 12. Rotte unterbringbar, da diese nur Thiere mit "plumpem Körper" umfassen soll und besonders die schlanken $\sigma^{\top} \sigma^{\top}$ von $O t$. frisius dem durchaus widerstreiten.

Fundort: Insel Borkum, wo dieser Otiorhynchus merkwürdiger Weise in dem nicht selten von der Meeresfluth überschwemmten Brackwassergebiete der Aufsenweide, nahe dem mittlen Hoop, in den vornehmlich aus Artemisia maritima bestehenden dichten, niedrigen Vegetationsflecken am Boden lebt. Dies Weilen im Verborgenen dürfte das voraussichtlich auch in den Wermuthgebieten der anderen friesischen Inseln nachweisbare Thier den Augen der Forscher entzogen haben.

\section{Neuheiten der schlesischen Käferfauna von 1895.}

Von

\section{J. Gerhardt in Liegnitz.}

An den Ergebnissen sind betheiligt die Herren: Rektor Kolbe (Klb.), Landgerichtsrath Kofsman n (Ks.), Lotterieeinnehmer und Kaufmann C. Schwarz (Schw.), Lehrer Scholz (Sch.), sämmtlich aus Liegnitz, Steuerinspektor Pietseh (P.) aus Ohlau und ich (G.).

1. Poecilus marginatus Dej. Im Angeschwemmten der Oder bei Ohlau und im Altvatergebirge in mehreren Stücken. Jedenfalls sind die Ohlauer Stücke aus den östlichen Hochsudeten herabgeschwemmt. $6 . \quad$ (P.)

2. Agabus striatulus Gyll. Ein Stück in einem kleinen Tümpel des sogenannten „Verlornen Wassers" bei Panten (Liegnitz), einem nur in sehr beifsen Sommern völlig trocknen, sehr schattigen und dumpfigen Erlicht. 6. (Klb.) 


\section{$2 \mathrm{BHL}$ Biodiversity Heritage Library}

Schneider, Oskar. 1896. "Zwei neue deutsche Käfer von Borkum." Deutsche entomologische Zeitschrift 1896(1), 177-179.

https://doi.org/10.1002/mmnd.48018960136.

View This Item Online: https://www.biodiversitylibrary.org/item/103427

DOI: https://doi.org/10.1002/mmnd.48018960136

Permalink: https://www.biodiversitylibrary.org/partpdf/235653

\section{Holding Institution}

Harvard University, Museum of Comparative Zoology, Ernst Mayr Library

\section{Sponsored by}

Harvard University, Museum of Comparative Zoology, Ernst Mayr Library

\section{Copyright \& Reuse}

Copyright Status: Public domain. The BHL considers that this work is no longer under copyright protection.

This document was created from content at the Biodiversity Heritage Library, the world's largest open access digital library for biodiversity literature and archives. Visit BHL at https://www.biodiversitylibrary.org. 